\title{
Effects of various remineralizing agents on the outcome of post-orthodontic white spot lesions (WSLs): a clinical trial
}

\author{
Sombir Singh ${ }^{1}$, Satinder Pal Singh ${ }^{1}$, Ashima Goyal', Ashok Kumar Utreja ${ }^{1}$ and Ashok Kumar Jena ${ }^{3^{*}}$
}

\begin{abstract}
Background: One of the most undesirable side effects of comprehensive orthodontic treatment is white spot lesions (WSLs). Despite many attempts at prevention of WSLs, its prevalence remains very high on debonding. There are many agents like fluoride toothpastes, fluoride varnishes, and fluoride mouth rinses, and casein phosphopeptide-amorphous calcium phosphate (CPP-ACP) is frequently used for the remineralization of WSLs. However, there is no consensus in the literature with respect to the success rates of these agents. Thus, the present study was designed to evaluate the efficacy of fluoride toothpaste alone and in combination with fluoride varnish and CPP-ACP plus crème in the remineralization of post-orthodontic WSLS.
\end{abstract}

Methods: Forty-five subjects in the age range of 16-25 years having at least one post-orthodontic WSL were included in the study. All the subjects were randomly divided into three groups (toothpaste group, varnish group, and CPP-ACP group). The efficacy of various remineralizing agents on the remineralization of WSLs was evaluated clinically and by DIAGNOdent immediately after debonding and subsequently after 1, 3, and 6 months of their use.

Results: Twice daily use of fluoride toothpaste alone had no significant effect on remineralization of WSLS at various intervals of observations ( $P=0.078$ ). Application of fluoride varnish along with twice daily use of fluoride toothpaste for 6 months significantly decreased the severity of WSLs $(P<0.01)$. Twice daily use of CPP-ACP plus crème along with fluoride toothpaste had significant effect on remineralization of WSLs at the end of 6 months of observation $(P<0.05)$. Between the group comparison showed that the mean visual and DIAGNOdent scores at various time intervals of observations were decreased more when fluoride varnish and CPP-ACP crème were used in addition to daily use of fluoride toothpaste, but the differences were not statistically significant $(P>0.05)$.

Conclusions: The use of fluoride varnish and CPP-ACP plus crème in addition to twice daily use of fluoride toothpaste had no additional benefit in the remineralization of post-orthodontic WSLS.

Keywords: Orthodontics, White spot lesion, Fluoride toothpaste, Fluoride varnish, CPP-ACP crème

\section{Background}

White spot lesions (WSLs) are one of the most undesirable side effects of multibracket orthodontic treatment and have been reported to occur in up to $96 \%$ of these patients $[1,2]$. Despite many attempts at comprehensive prophylaxis aiming at prevention of WSLs, the prevalence of WSLs remain as high as $61 \%$ on debonding [3]. It is generally believed that these lesions will recover

\footnotetext{
* Correspondence: drashokkjena@gmail.com

${ }^{3}$ Department of Dental Surgery, All India Institute of Medical Sciences Sijua, Dumduma, Bhubaneswar, Odisha, India

Full list of author information is available at the end of the article
}

through natural remineralization through saliva, once the orthodontic appliances have been removed and oral hygiene is restored [4]. However, natural remineralization through saliva accounts for mineral gain in the surface layer of WSLs has little improvement on the esthetics and structural properties of the deeper lesions [5]. The complete elimination of WSLs is unlikely [6], and some WSLs last for up to 5-12 years [7]. Therefore, it becomes necessary to apply remineralizing agents to repair the deeper parts of WSLs for better esthetics.

The commonly used agents for the treatment of WSLs are topical fluorides [8-11]. These include fluoride 
toothpastes [12-14], fluoride varnishes [15], and fluoride mouth rinses [4, 16]. Recently introduced casein phosphopeptide-amorphous calcium phosphate (CPP$\mathrm{ACP}$ ) is frequently used for the treatment of WSLs [17-20]. Most topical fluoride products rely on patient compliance and render some of these methods less efficacious. The topical fluoride delivery methods such as application of varnish and other remineralizing agents provide adequate control and reduce the need for patient compliance $[15,18]$. However, there is no consensus in the literature with respect to the success rates of these agents. Thus, the present study was designed to evaluate the efficacy of fluoride toothpaste alone and in combination with fluoride varnish and CPP-ACP plus crème in the remineralization of post-orthodontic WSLs. The null hypothesis which was tested in the present study was that fluoride toothpaste alone and in combination with fluoride varnish and CPP-ACP crème were equally effective in the remineralization of post-orthodontic WSLs.

\section{Methods}

The study was approved by the Institute Review Board (NK/1155/MDS/4037-38).

\section{Sample size calculation}

Sample size of 36 was calculated, demonstrating a $20 \%$ decreases in the severity of WSLs between the control and experimental groups, power of $80 \%$, level of significance as $95 \%$, and the estimated disease reduction in the control group as $50 \%$. But considering the expected loss to follow-up as $25 \%$, the final sample size was inflated to 45 .

\section{Assessment for eligibility}

Subjects in the age range of 16-25 years who just completed comprehensive orthodontic treatment with at least one WSL in a specific mouth area were considered as inclusion criteria, and subjects with cleft lip and palate deformities, orofacial syndrome, hypoplastic enamel defects, and multiple restorations on the facial surfaces and with known history of allergy to milk protein were considered as exclusion criteria. A written informed consent of minors' parents was obtained from each patient.

\section{Enrollment}

All the subjects were randomly allocated to three groups of 15 each using block randomization approach with 3 blocks, having a block size of 5 subjects each. Of all subjects recruited in the study $(n=45 ; M=21, F=24), 4$ $(M=3, F=1)$ subjects were lost during the follow-up period.

\section{Allocation}

Groups I $(n=14 ; M=6, F=8)$, II $(n=13 ; M=5, F=8)$, and III ( $n=14 ; M=7, F=7)$ included subjects who used toothpaste, fluoride varnish, and $\mathrm{CPP}-\mathrm{ACP}$ plus crème, respectively. A random code number were allotted to each patient at the beginning of study. The patients and the data evaluators were blinded with respect to the type of remineralizing agents used. In each subject, the efficacy of remineralizing agents was assessed both by subjective and objective methods immediately after debonding $\left(T_{0}\right)$, i.e., prior to application of remineralizing agents and subsequently 1 month $\left(T_{1}\right), 3$ months $\left(T_{2}\right)$, and 6 months $\left(T_{3}\right)$ of use of various remineralizing agents. A participant flow chart and intervention allocation is shown in Fig. 1.

Group I (control group) subjects were advised to brush twice daily with $1000 \mathrm{ppm}$ fluoride toothpaste (Colgate total $^{\circ}$ Colgate-Palmolive Company) during the follow-up period. No other fluoride supplements were allowed for use.

In group II (varnish group), fluoride varnish (5 \% NaF, Fluoritop-SR ${ }^{\oplus}$ ICPA Health Products Ltd.) was applied. The labial surface of each tooth surface was polished by non-fluoridated pumice powder and was rinsed and dried thoroughly. Approximately $1 \mathrm{ml}$ of varnish was applied by paint-on technique on the labial surface of each tooth in both the jaws from central incisor to the first molar on either side. After varnish application, patients were advised not to drink water for at least $30 \mathrm{~min}$, eat for $4 \mathrm{~h}$, and brush their teeth until the next day morning. The subjects were then advised to brush their teeth twice daily with $1000 \mathrm{ppm}$ fluoride toothpaste (Colgate total $^{\circ}$ Colgate-Palmolive Company). No other fluoride supplements were allowed for use.

The group III (CPP-ACP group) subjects were advised to use pea size CPP-ACP plus crème (GC Tooth Mousse, Asia Pty. Ltd, Japan) on the tooth surfaces using a clean finger twice daily following brushing their teeth with $1000 \mathrm{ppm}$ fluoride toothpaste (Colgate total ${ }^{\circ}$ Colgate-Palmolive Company). The subjects were advised to keep the CPP-ACP plus crème over the teeth surfaces for at least $3 \mathrm{~min}$ before rinsing the mouth. The CPP$\mathrm{ACP}$ plus crème contains $900 \mathrm{ppm}$ of fluoride along with $\mathrm{CPP}-\mathrm{ACP}$ crème, releases calcium and phosphate and helps in maintaining a supersaturated solution in the oral cavity. After the application of CPP-ACP plus crème, the subjects were advised not to drink water or eat anything for at least $30 \mathrm{~min}$. No other fluoride supplements were allowed for use.

\section{Outcome measures}

The WSLs were recorded on a standard proforma. The labial surface of each tooth in both the jaws from central incisor to the first molar on either side was considered in the study. The teeth were polished by non-fluoridated pumice powder and were rinsed and dried thoroughly for subjective and objective recording of WSLs. In 


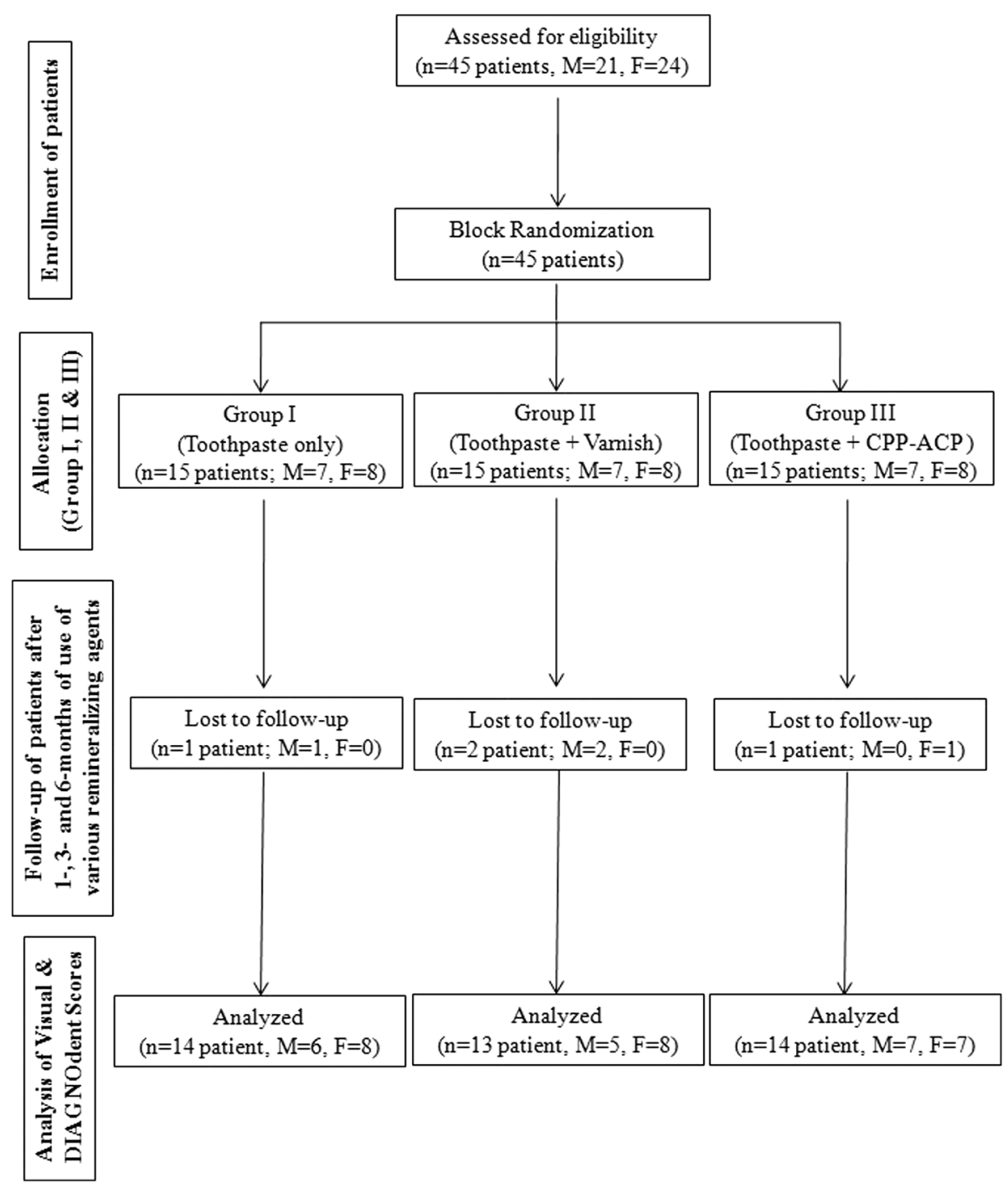

Fig. 1 Flow chart showing patient allocation

subjective method, the scores and criteria proposed by Boyd [14] were used (Table 1). The DIAGNOdent was used to quantify the WSLs objectively. Measurements with the DIAGNOdent were performed and calibrated for each patient on a sound enamel (incisal third of the central incisor) before actual readings. The teeth were scanned carefully with the tip held in contact with the

Table 1 Scores and criteria followed for the subjective evaluation of the WSLS

\begin{tabular}{|c|c|}
\hline Scores & Criteria \\
\hline 0 & No visible white spot or surface disruption (no decalcification) \\
\hline 1 & Visible white spot without surface disruption (mild decalcification) \\
\hline 2 & $\begin{array}{l}\text { Visible white spot lesion having a roughened surface but not } \\
\text { requiring restoration (moderate decalcification) }\end{array}$ \\
\hline 3 & Visible white spot lesion requiring restoration (severe decalcification) \\
\hline
\end{tabular}

tooth surface and tilted around the measuring site so that fluorescence could be collected from all directions. The maximum reading was recorded. Each labial surface was measured thrice (by AG), and finally, a mean of all the three readings was calculated.

For each subject, the scores of all the teeth were added and the mean was considered for statistical analysis.

\section{Statistical analysis}

A master file was made in Microsoft excel software and the data statistically analyzed on a computer using SPSS software version 17 (Statistical Packages for the Social Sciences, Chicago, IL). Descriptive statistics were used. The ANOVA and Bonferroni were used for within the group comparisons. The Kruskal-Wallis test and ANOVA 
were used for between the group comparisons. A $P$ value of $<0.05$ was considered as level of statistical significance.

\section{Results}

The mean age of the subjects at the beginning of the study was $18.93 \pm 2.97,19.08 \pm 3.57$, and $16.93 \pm 3.24$ years for group I, group II, and group III, respectively $(P=0.953)$. Total 913 teeth were examined. At the beginning of the study, a total of 556 WSLs were recorded subjectively, of which 230 and 326 were present among males and females, respectively.

The changes in the visual scores are described in Table 2. The mean visual score at the beginning of study was comparable among the three groups $(P=0.733)$. The mean scores in all groups were decreased at $T_{1}, T_{2}$, and $T_{3}$ observation. In group I, there was no significant change in the mean visual scores at various time of observation $(P=0.078)$. In group II, the change in the visual scores was significant $(P<0.05)$. The visual scores in group II subjects decreased significantly at $T_{3}$ compared to $T_{0}(P<0.01)$. In group III, the change in the visual scores was significant $(P<0.01)$. The mean visual scores in group III subjects decreased significantly at $T_{2}(P<0.05)$ and $T_{3}(P<0.05)$ compared to $T_{0}$. The changes in the visual scores between the groups at various time intervals of observation $\left(T_{1}, T_{2}\right.$, and $\left.T_{3}\right)$ are described in Table 3. The mean visual scores at $T_{1}, T_{2}$, and $T_{3}$ were decreased in all the groups, but the decrease in group II and group III was more compared to the decrease in group I. However, the decrease in the mean visual scores among three groups at various time intervals of observation was comparable $(P>0.05)$.

The changes in the DIAGNOdent scores are described in Table 4. The mean DIAGNOdent score was marginally increased in all groups at the end of $T_{1}$ but decreased at the end of $T_{2}$ and $T_{3}$; the differences were statistically comparable. The changes in the DIAGNOdent scores between the groups at various time intervals of observation $\left(T_{0}, T_{1}, T_{2}\right.$, and $\left.T_{3}\right)$ are described in Table 5. The mean DIAGNOdent scores in group II and group III were decreased more compared to the decrease in group I; however, the changes were comparable among the three groups $(P>0.05)$.

\section{Discussion}

Although the prevention of development of WSLs during comprehensive orthodontic treatment is the goal of every orthodontist, its prevalence is still quite high [21]. Treatment of WSLs present a significant challenge in achieving esthetic excellence [22]. These WSLs can last as long as 5-12 years [7], as natural remineralization through saliva involving mineral gain in the surface layer

Table 2 Description of visual scores among subjects of three groups at various time intervals of observation

\begin{tabular}{|c|c|c|c|c|c|}
\hline \multirow[t]{2}{*}{ Groups } & \multirow{2}{*}{$\begin{array}{l}\text { Time } \\
\text { intervals }\end{array}$} & \multirow{2}{*}{$\begin{array}{l}\text { Visual scores } \\
\text { mean } \pm S D\end{array}$} & \multirow{2}{*}{$\begin{array}{l}\text { Significance } \\
(P \text { value })\end{array}$} & \multicolumn{2}{|c|}{ Comparison between various time intervals of observation (intra-group) } \\
\hline & & & & Comparison & $P$ value \\
\hline \multirow[t]{6}{*}{ Group I } & $T_{0}$ & $15.71 \pm 7.94$ & \multirow[t]{6}{*}{$0.078 \mathrm{NS}$} & $T_{0}-T_{1}$ & $1.000 \mathrm{NS}$ \\
\hline & $T_{1}$ & $12.14 \pm 8.41$ & & $T_{0}-T_{2}$ & $0.582 \mathrm{NS}$ \\
\hline & $T_{2}$ & $10.57 \pm 8.18$ & & $T_{0}-T_{3}$ & $0.067 \mathrm{NS}$ \\
\hline & \multirow[t]{3}{*}{$T_{3}$} & \multirow[t]{3}{*}{$07.71 \pm 7.66$} & & $T_{1}-T_{2}$ & $1.000 \mathrm{NS}$ \\
\hline & & & & $T_{1}-T_{3}$ & 0.910 NS \\
\hline & & & & $T_{2}-T_{3}$ & $1.000 \mathrm{NS}$ \\
\hline \multirow[t]{6}{*}{ Group II } & $T_{0}$ & $12.31 \pm 6.45$ & \multirow[t]{6}{*}{$0.012^{*}$} & $T_{0}-T_{1}$ & $0.676 \mathrm{NS}$ \\
\hline & $T_{1}$ & $08.85 \pm 6.22$ & & $T_{0}-T_{2}$ & 0.169 NS \\
\hline & $T_{2}$ & $07.46 \pm 5.47$ & & $T_{0}-T_{3}$ & $0.008^{* *}$ \\
\hline & \multirow[t]{3}{*}{$T_{3}$} & \multirow[t]{3}{*}{$05.00 \pm 3.03$} & & $T_{1}-T_{2}$ & $1.000 \mathrm{NS}$ \\
\hline & & & & $T_{1}-T_{3}$ & 0.473 NS \\
\hline & & & & $T_{2}-T_{3}$ & $1.000 \mathrm{NS}$ \\
\hline \multirow[t]{6}{*}{ Group III } & $T_{0}$ & $15.50 \pm 12.45$ & \multirow[t]{6}{*}{$0.008^{* *}$} & $T_{0}-T_{1}$ & $1.000 \mathrm{NS}$ \\
\hline & $T_{1}$ & $12.28 \pm 6.83$ & & $T_{0}-T_{2}$ & $0.035^{*}$ \\
\hline & $T_{2}$ & $06.85 \pm 4.91$ & & $T_{0}-T_{3}$ & $0.018^{*}$ \\
\hline & \multirow[t]{3}{*}{$T_{3}$} & \multirow[t]{3}{*}{$06.14 \pm 5.24$} & & $T_{1}-T_{2}$ & 0.462 NS \\
\hline & & & & $T_{1}-T_{3}$ & 0.277 NS \\
\hline & & & & $T_{2}-T_{3}$ & $1.000 \mathrm{NS}$ \\
\hline
\end{tabular}

$T_{0}$ prior to application of remineralizing agents, $T_{1} 1$ month after the use of remineralizing agents, $T_{2} 3$ months after the use of remineralizing agents, $T_{3} 6$ months after the use of remineralizing agents, NS non-significant

${ }^{*} P<0.05 ;{ }^{* *} P<0.01$ 
Table 3 Between the group comparisons of visual scores at various time intervals of observation

\begin{tabular}{lllll}
\hline $\begin{array}{l}\text { Time } \\
\text { intervals }\end{array}$ & Groups & & $\begin{array}{l}\text { Significance } \\
\text { (P value) }\end{array}$ \\
\cline { 2 - 4 } & Group I & Group II & Group III & \\
\hline$T_{0}$ & $15.71 \pm 7.94$ & $12.31 \pm 6.45$ & $15.50 \pm 12.45$ & $0.560 \mathrm{NS}$ \\
$T_{1}$ & $12.14 \pm 8.41$ & $08.85 \pm 6.22$ & $12.28 \pm 6.83$ & $0.387 \mathrm{NS}$ \\
$T_{2}$ & $10.57 \pm 8.18$ & $07.46 \pm 5.47$ & $06.85 \pm 4.91$ & $0.416 \mathrm{NS}$ \\
$T_{3}$ & $07.71 \pm 7.66$ & $05.00 \pm 3.03$ & $06.14 \pm 5.24$ & $0.863 \mathrm{NS}$ \\
\hline
\end{tabular}

$T_{0}$ prior to application of remineralizing agents, $T_{1} 1$ month after the use of remineralizing agents, $T_{2} 3$ months after the use of remineralizing agents, $T_{3}$ 6 months after the use of remineralizing agents, NS non-significant

of WSLs has little improvement on the esthetic and structural properties of the deeper lesions [5]. It therefore becomes important to apply remineralizing agents topically on the tooth surface after debonding to repair the deeper part of the WSLs for better esthetic and structural reinforcement.

The integrity of enamel in the oral cavity under normal conditions is influenced by the dynamic process comprising of alternating periods of demineralization and remineralization. Lot of efforts has been made for reversing the process of demineralization, and fluoride has always remained the gold standard. The presence of trace quantities of fluoride plays a significant role to drive the process in the direction of remineralization [23]. Also, an inverse association between plaque calcium and phosphate levels with enamel demineralization has been found [24]. Thus, efforts have been made to increase the level of fluoride, calcium, and phosphate ions in immediate vicinity of the teeth to enhance the process

Table 4 Description of DIAGNOdent scores at various time intervals of observation among subjects of three groups

\begin{tabular}{llll}
\hline Groups & $\begin{array}{l}\text { Time } \\
\text { intervals }\end{array}$ & $\begin{array}{l}\text { DIAGNOdent scores } \\
\text { Mean } \pm \text { SD }\end{array}$ & $\begin{array}{l}\text { Significance } \\
(P \text { value })\end{array}$ \\
\hline Group I & $T_{0}$ & $131.43 \pm 41.42$ & 0.744 NS \\
& $T_{1}$ & $134.00 \pm 45.14$ & \\
& $T_{2}$ & $121.93 \pm 37.31$ & \\
Group II & $T_{3}$ & $118.71 \pm 46.46$ & 0.378 NS \\
& $T_{0}$ & $105.54 \pm 25.20$ & \\
& $T_{1}$ & $107.67 \pm 27.73$ & \\
& $T_{2}$ & $102.61 \pm 34.90$ & \\
Group III & $T_{3}$ & $88.85 \pm 30.41$ & \\
& $T_{0}$ & $119.07 \pm 36.27$ & \\
& $T_{1}$ & $113.57 \pm 40.54$ & \\
& $T_{2}$ & $118.78 \pm 46.19$ & \\
& $T_{3}$ & $100.64 \pm 42.33$ & \\
\hline
\end{tabular}

$T_{0}$ prior to application of remineralizing agents, $T_{1} 1$ month after the use of remineralizing agents, $T_{2} 3$ months after the use of remineralizing agents, $T_{3}$ 6 months after the use of remineralizing agents, NS non-significant
Table 5 Between the group comparisons of DIAGNOdent scores at various time intervals of observation

\begin{tabular}{|c|c|c|c|c|}
\hline \multirow{3}{*}{$\begin{array}{l}\text { Time } \\
\text { intervals }\end{array}$} & \multicolumn{3}{|l|}{ Groups } & \multirow{3}{*}{$\begin{array}{l}\text { Significance } \\
\text { ( } P \text { value })\end{array}$} \\
\hline & Group I & Group II & Group III & \\
\hline & Mean $\pm S D$ & Mean $\pm S D$ & Mean $\pm S D$ & \\
\hline$T_{0}$ & $131.43 \pm 41.42$ & $105.54 \pm 25.20$ & $119.07 \pm 36.27$ & $0.175 \mathrm{NS}$ \\
\hline$T_{1}$ & $134.00 \pm 45.14$ & $107.67 \pm 27.73$ & $113.57 \pm 40.54$ & $0.900 \mathrm{NS}$ \\
\hline$T_{2}$ & $121.93 \pm 37.31$ & $102.61 \pm 34.90$ & $118.78 \pm 46.19$ & $0.415 \mathrm{NS}$ \\
\hline$T_{3}$ & $118.71 \pm 46.46$ & $88.85 \pm 30.41$ & $100.64 \pm 42.33$ & 0.168 NS \\
\hline
\end{tabular}

of remineralization. Various agents like two solution fluoride rinses [25] and tri-calcium phosphate nanocomplexes with fluoride ions (Clinpro tooth crème) have been introduced. Milk product-based complexes like CPP-ACP crème have also been tried to deliver calcium and phosphate ions to the tooth surface [4]. Many animal and human experiments also confirmed that CPPACP nano-complexes have anticariogenic activity [17, $18,26]$. Thus, the efficacy of fluoride varnish that releases traces of fluoride ions and CPP-ACP plus crème that releases fluoride, calcium, and phosphate ions in immediate vicinity of WSLs were tested in this study.

The DIAGNOdent is a laser fluorescence device used to quantify the enamel demineralization. The main unit generates laser light with a wavelength of $655 \mathrm{~nm}$, which is absorbed by both organic and inorganic material in the tooth and re-emitted as fluorescence within the infrared region. In the presence of caries, fluorescence increases and the change is registered as an increased digital number. The mechanism underlying the enhanced fluorescence in the presence of caries has yet to be established but is presumed to result from the integration of bacterial metabolites rather than crystalline disintegration. The DIAGNOdent readings should always be interpreted with caution because DIAGNOdent readings are often affected by stains, calculus, and plaque [27] and bacterial metabolites [28], which are not directly related to the problems perceived by patients or doctors. Therefore, the combined use of technology-based methods and visual assessment is the best approach for evaluating the WSLs.

We observed that the use of $1000 \mathrm{ppm}$ of fluoride toothpaste twice daily alone had beneficial effect on the regression of WSLs. Similar to our observation, Hoffman et al. [29] also observed that the use of traditional fluoride toothpaste alone was effective in improving white spot lesions during orthodontic treatment. However, in contrast to our observation, many previous studies $[13,16]$ reported that the toothpaste alone was not effective in reducing the post-orthodontic WSLs. Zantiner et al. [12] also observed that the use of either sodium fluoride toothpaste 
(1500 ppm) or toothpaste-containing amine fluoride (1250 ppm) for 6 months had no effect on the WSLs. However, Alexander et al. [16] reported that brushing twice daily with 5000-ppm fluoride toothpaste was more effective in the reversal of enamel demineralization than tooth brushing with a 1000 ppm of fluoride toothpaste. The concentration and doses of fluoride application are controversial. Fluoride agents that release a high dose of fluoride initially (burst effect) are more effective for increasing enamel resistance against decalcification [30]. A low concentration of fluoride is more effective in enamel remineralization [31]. The high dose of fluoride physically blocks the surface layer of enamel to penetration of calcium ions to subsurface layers [32]. Thus, high dose of fluoride is recommended in inhibiting lesion formation and low dose of fluoride for the remineralization and controlling lesion progression.

The results of the present study however revealed that brushing twice daily with $1000 \mathrm{ppm}$ of fluoride toothpaste along with $5 \% \mathrm{NaF}$ varnish or CPP-ACP plus crème was more effective in remineralizing the WSLs. But their efficacy was comparable to the remineralization efficacy of fluoride toothpaste alone at various intervals of observations. When fluoride varnish is applied to the tooth surface, it forms a reservoir of fluoride ions which get released slowly and thus continuously reacted with the hydroxy-apatite crystals of enamel over a long period of time leading to deeper penetration and formation of fluoro-hydroxyapatite crystals. Similar to our observation, many authors also observed reversal in the enamel lesions following application of fluoride varnish $[14,16]$. Boyd [14] found that twice daily use of 1100-ppm fluoride toothpaste along with $0.05 \% \mathrm{NaF}$ rinse or topical application of $0.4 \%$ $\mathrm{SnF}_{2}$ gel had additional protection against enamel decalcification. Feagin [33] reported that fluoride increased the rate of calcium phosphate deposition during remineralization of acid-softened enamel and itself got incorporated into the mineral thus formed. Brushing twice daily with 1000-ppm fluoride toothpaste results in the formation of $\mathrm{CaF}_{2}$ and also deposition of fluoride in the superficial layers of enamel, in contrast to the fluoride varnish in which the slow release of fluoride ions results in the formation of more stable fluoro-hydroxyapatite compound [34].

The present study showed better remineralization of WSLs following the use of CPP-ACP plus crème along with $1000 \mathrm{ppm}$ of fluoride toothpaste. But between the group comparison showed no additional remineralization efficacy of CPP-ACP plus crème when used with $1000 \mathrm{ppm}$ of fluoride toothpaste. However, literature supports that application of CPP-ACP crème along with fluoride toothpaste on daily basis had better remineralization potential than once professional application of fluoride varnish and twice daily use of fluoride toothpaste $[35,36]$. The synergistic effect of CPP-ACP and fluoride in reducing the WSLs is due to the formation of CPP-stabilized amorphous calcium fluoride phosphate, resulting in increased concentration of bioavailable calcium and phosphate ions [37]. The CPP-bound ACP acts as a reservoir of calcium phosphate ions, including the neutral ion pair $\mathrm{CaHPO}_{4}$ which is formed in the presence of acid [38]. When acid is formed by the plaque bacteria, the CPPbound ACP buffers the plaque $\mathrm{pH}$, and in doing so, it dissociates to calcium and phosphate ions including $\mathrm{CaHPO}_{4}$. The increased plaque calcium and phosphate ions offset any fall in $\mathrm{pH}$, thereby preventing enamel demineralization. In the presence of fluorides, formation of CPP-ACFP nano-complexes takes place, and when the $\mathrm{pH}$ falls, breakage of the nano-complex leads to formation of calcium ions, phosphate ions, and neutral species $\mathrm{CaHPO}_{4}$ and HF. These ions following concentration gradient move inside the subsurface lesion, thus leading to formation of fluorapatite. Feagin [33] observed that in the presence of fluoride, the rate of calcium and phosphate deposition increased during remineralization and accelerated the rate of enamel surface rehardening. Similarly, Koulourides et al. [39] also found a relative increase in the rate of calcium and phosphate deposition from solutions containing fluoride. Akin et al. [40] found $58 \%$ reduction in the WSLs following 6 months of use of CPP-ACP crème twice daily along with fluoride toothpaste. Andersson et al. [41] observed that daily topical application of a dental crème containing CPP-ACP for 3 months followed by a 3-month period of daily tooth brushing with fluoridated toothpaste helped in the complete elimination of the post-orthodontic WSLs. Llena et al. [17] observed that 4-week use of CPPACFP was superior to duraphate fluoride varnish in remineralizing smooth surface WSLs. However, Beerns et al. [18] observed that the use of CPP-ACFP crème for 12 weeks had no clinical advantage over normal hygiene in the remineralization of WSLs.

Although we observed that the additional use of fluoride varnish and CPP-ACP plus crème to daily use of fluoride toothpaste was more effective in reducing the severity of WSLs, this effectiveness was comparable with the remineralization efficacy of fluoride toothpaste alone. Thus, orthodontists can routinely prescribe traditional fluoride toothpastes for the management of postorthodontic WSLs. However, more similar studies are required to confirm the present findings. The limitation of the present study was that the visual and DIAGNOdent scores of each tooth were added to find out a mean score for a subject. However, for better results, the mean visual and DIAGNOdent scores for each individual tooth would have been calculated separately and considered for statistical analysis. 


\section{Conclusions}

1. The use of $1000 \mathrm{ppm}$ of fluoride toothpaste twice daily was effective in the remineralization of postorthodontic WSLs.

2. The use of $5 \% \mathrm{NaF}$ varnish in addition to twice daily use of $1000 \mathrm{ppm}$ of fluoride toothpaste had no additional beneficial effect in the remineralization of post-orthodontic WSLs.

3. Twice daily use of CPP-ACP plus crème along with twice daily use of $1000 \mathrm{ppm}$ of fluoride toothpaste had no added benefit in the remineralization of post-orthodontic WSLs.

\section{Authors' contributions}

Jena AK and Singh SP formulated the research question and designed the study. Singh S performed the clinical assessments and collected the data; Goyal A, Singh SP and Utreja AK supervised the study, checked the data. Jena AK prepared the manuscript and did correspondence. All authors read and approved the final manuscript.

\section{Competing interests}

The authors declare that they have no competing interests.

\begin{abstract}
Author details
${ }^{1}$ Unit of Orthodontics, Oral Health Sciences Centre Post Graduate Institute of Medical Education and Research, Sector-12, Chandigarh, India. ${ }^{2}$ Unit of Pedodontics and Preventive Dentistry, Oral Health Sciences Centre Post Graduate Institute of Medical Education and Research, Sector-12, Chandigarh, India. ${ }^{3}$ Department of Dental Surgery, All India Institute of Medical Sciences Sijua, Dumduma, Bhubaneswar, Odisha, India.
\end{abstract}

Received: 5 May 2016 Accepted: 7 July 2016

\section{Published online: 02 August 2016}

\section{References}

1. Artun J, Brobakken BO. Prevalence of carious white spots after orthodontic treatment with multibonded appliances. Eur J Orthod. 1986;8:229-34.

2. Lone EA, Utreja AK, Singh SP, Jena AK. Effect of multibracket orthodontic appliance on frequency and severity of enamel demineralization-a prospective study. J Dent Special. 2015;3:36-9.

3. Ogaard B, Larsson E, Henriksson T, Birkhed D, Bishara SE. Effects of combined application of antimicrobial and fluoride varnishes in orthodontic patients. Am J Orthod Dentofacial Orthop. 2001:120:28-35.

4. Ogaard B, Rølla G, Arends J, ten Cate JM. Orthodontic appliances and enamel demineralization. Part 2. Prevention and treatment of lesions. Am J Orthod Dentofacial Orthop. 1988;94:123-8.

5. Cochrane NJ, Cai F, Huq NL, Burrow MF, Reynolds EC. New approaches to enhanced remineralization of tooth enamel. J Dent Res. 2010;89:1187-97.

6. Al-Khateeb S, Forsberg CM, de Josselin de Jong E, Angmar-Månsson B. A longitudinal laser fluorescence study of white spot lesions in orthodontic patients. Am J Orthod Dentofacial Orthop. 1998;113:595-602.

7. Shungin D, Olsson Al, Persson M. Orthodontic treatment-related white spot lesions: a 14-year prospective quantitative follow-up, including bonding material assessment. Am J Orthod Dentofacial Orthop. 2010;138:136-8.

8. Huang GJ, Roloff-Chiang B, Mills BE, Shalchi S, Spiekerman C, Korpak AM, et al. Effectiveness of MI Paste Plus and PreviDent fluoride varnish for treatment of white spot lesions: a randomized controlled trial. Am J Orthod Dentofacial Orthop. 2013;143:31-41.

9. Borzabadi-Farahani A, Borzabadi E, Lynch E. Nanoparticles in orthodontics, a review of antimicrobial and anti-caries applications. Acta Odontol Scand. 2014:72:413-7.

10. Alessandri Bonetti G, Pazzi E, Zanarini M, Marchionni S, Checchi L. The effect of zinc-carbonate hydroxyapatite versus fluoride on enamel surfaces after interproximal reduction. Scanning. 2014;36:356-61.

11. Montasser MA, Taha M. Effect of enamel protective agents on shear bond strength of orthodontic brackets. Prog Orthod. 2014;15:34.
12. Zantner C, Martus P, Kielbassa AM. Clinical monitoring of the effect of fluorides on long-existing white spot lesions. Acta Odontol Scand. 2006;64:115-22.

13. Sonesson $M$, Twetman $S$, Bondemark $L$. Effectiveness of high-fluoride toothpaste on enamel demineralization during orthodontic treatment-a multicenter randomized controlled trial. Eur J Orthod. 2014;36:678-82.

14. Boyd RL. Comparison of three self-applied topical fluoride preparations for control of decalcification. Angle Orthod. 1993;63:25-30.

15. Jena AK, Singh SP, Utreja AK. Efficacy of resin modified glass ionomer cement varnish in the prevention of white spot lesions during comprehensive orthodontic treatment: a split mouth study. J Orthod. 2015;42:200-7.

16. Alexander SA, Ripa LW. Effects of self-applied topical fluoride preparations in orthodontic patients. Angle Orthod. 2000;70:424-30.

17. Llena C, Leyda AM, Forner L. CPP-ACP and CPP-ACFP versus fluoride varnish in remineralisation of early caries lesions. A prospective study. Eur J Paediatr Dent. 2015:16:181-6.

18. Beerens MW, van der Veen MH, van Beek H, ten Cate JM. Effects of casein phosphopeptide-amorphous calcium fluoride phosphate paste on white spot lesions and dental plaque after orthodontic treatment: a 3-month follow-up. Eur J Oral Sci. 2010:118:610-7.

19. Paganelli C, Zanarini M, Pazzi E, Marchionni S, Visconti L, Alessandri BG. Interproximal enamel reduction: an in vivo study. Scanning. 2015;37:73-81.

20. Ladhe KA, Sastri MR, Madaan JB, Vakil KK. Effect of remineralizing agents on bond strength of orthodontic brackets: an in vitro study. Prog Orthod. 2014;15:28.

21. Boersma JG, van der Veen MH, Lagerweil MD, Bokhout B, Prahl-Andersen B. Caries prevalence measured with QLF after treatment with fixed orthodontic appliances: influencing factors. Caries Res. 2005;39:41-7.

22. Heymann GC, Grauer D. A contemporary review of white spot lesions in orthodontics. J Esthet Restor Dent. 2013:25:85-95.

23. Silverstone LM. Remineralization phenomena. Caries Res. 1977;11:59-84.

24. Schamschula RG, Adkins BL, Barmes DE, Charlton G, Davey BG. Caries experience and the mineral content of plaque in a primitive population of New Guinea. J Dent Res. 1977:56:C62-70.

25. Chow LC, Takagi S, Carey CM, Sieck BA. Remineralization effects of a twosolution fluoride mouthrinse: an in-situ study. J Dent Res. 2000:79:991-5.

26. Hegde MN, Moany A. Remineralization of enamel subsurface lesions with casein phosphopeptide-amorphous calcium phosphate: a quantitative energy dispersive X-ray analysis using scanning electron microscopy: an in-vitro study. J Conser Dent. 2012;15:61-7.

27. Pretty IA. Caries detection and diagnosis: novel technologies. J Dent. 2006; 34:727-39.

28. Lussi A, Hibst R, Paulus R. DIAGNOdent: an optical method for caries detection. J Dent Res. 2004;83 Suppl 1:C80-83.

29. Hoffman DA, Clark AE, Rody Jr WJ, McGorray SP, Wheeler TT. A prospective randomized clinical trial into the capacity of a toothpaste containing NovaMin to prevent white spot lesions and gingivitis during orthodontic treatment. Prog Orthod. 2015;16:25

30. Basdra EK, Huber H, Komposch G. Fluoride released from orthodontic bonding agents alters the enamel surface and inhibits enamel demineralization in vitro. Am J Orthod Dentofacial Orthop. 1996:109:466-72.

31. Linton JL. Quantitative measurements of remineralization of incipient caries. Am J Orthod Dentofacial Orthop. 1996:110:590-7.

32. Ogaard B. Prevalence of white spot lesions in 19-year-olds: a study on untreated and orthodontically treated persons 5 years after treatment. Am J Orthod Dentofacial Orthop. 1989;96:423-7.

33. Feagin FF. Calcium, phosphate and fluoride deposition on enamel surfaces. Calcified Tissue Res. 1971;8:154-64.

34. Forward GC. Action and interaction of fluoride in dentifrices. Community Dent Oral Epidemiol. 1980;8:257-66.

35. Dubey M, Goyal M, Utreja AK, Gauba K, Jena AK. Use of casein phosphopeptide-amorphous calcium phosphate (CPP-ACP) crème along with fluoride dentifrice is beneficial in the remineralization of demineralized enamel. Int J Oral Health. 2013:9:33-40.

36. Reynolds EC, Cai F, Cochrane NJ, Shen P, Walker GD, Morgan MV, et al. Fluoride and casein phosphopeptide-amorphous calcium phosphate. J Dent Res. 2008;87:344-8.

37. Cross KJ, Huq NL, Stanton DP, Sum M, Reynolds EC. NMR studies of a novel calcium, phosphate and fluoride delivery vehicle alphs (S1)-casein (59-79) by stabilized amorphous calcium fluoride phosphate nanocomplexes. Biomaterials. 2004;25:5061-9.

38. Reynolds EC. Remineralization of enamel subsurface by casein phosphopeptidestabilized calcium phosphate solutions. J Dent Res. 1997;76:1587-95. 
39. Koulourides T, Cueto H, Pigman W. Rehardening of softened enamel surfaces of human teeth by solutions of calcium phosphates. Nature. 1961;189:226-7.

40. Akin M, Basciftci FA. Can white spot lesions be treated effectively? Angle Orthod. 2012;82:770-5.

41. Andersson A, Sköld-Larsson K, Hallgren A, Petersson LG, Twetman S. Effect of a dental cream containing amorphous cream phosphate complexes on white spot lesion regression assessed by laser fluorescence. Oral Health Prev Dent. 2007;5:229-33.

\section{Submit your manuscript to a SpringerOpen ${ }^{\circ}$ journal and benefit from:}

- Convenient online submission

- Rigorous peer review

- Immediate publication on acceptance

- Open access: articles freely available online

- High visibility within the field

- Retaining the copyright to your article

Submit your next manuscript at $>$ springeropen.com 